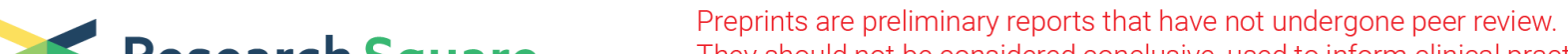 $\begin{array}{ll}\text { Research Square } & \text { They should not be considered conclusive, used to inform clinical practice, } \\ \text { or referenced by the media as validated information. }\end{array}$
}

\section{Gene Expression Profiling For Diagnosis of Multiple Primary Malignant Tumors}

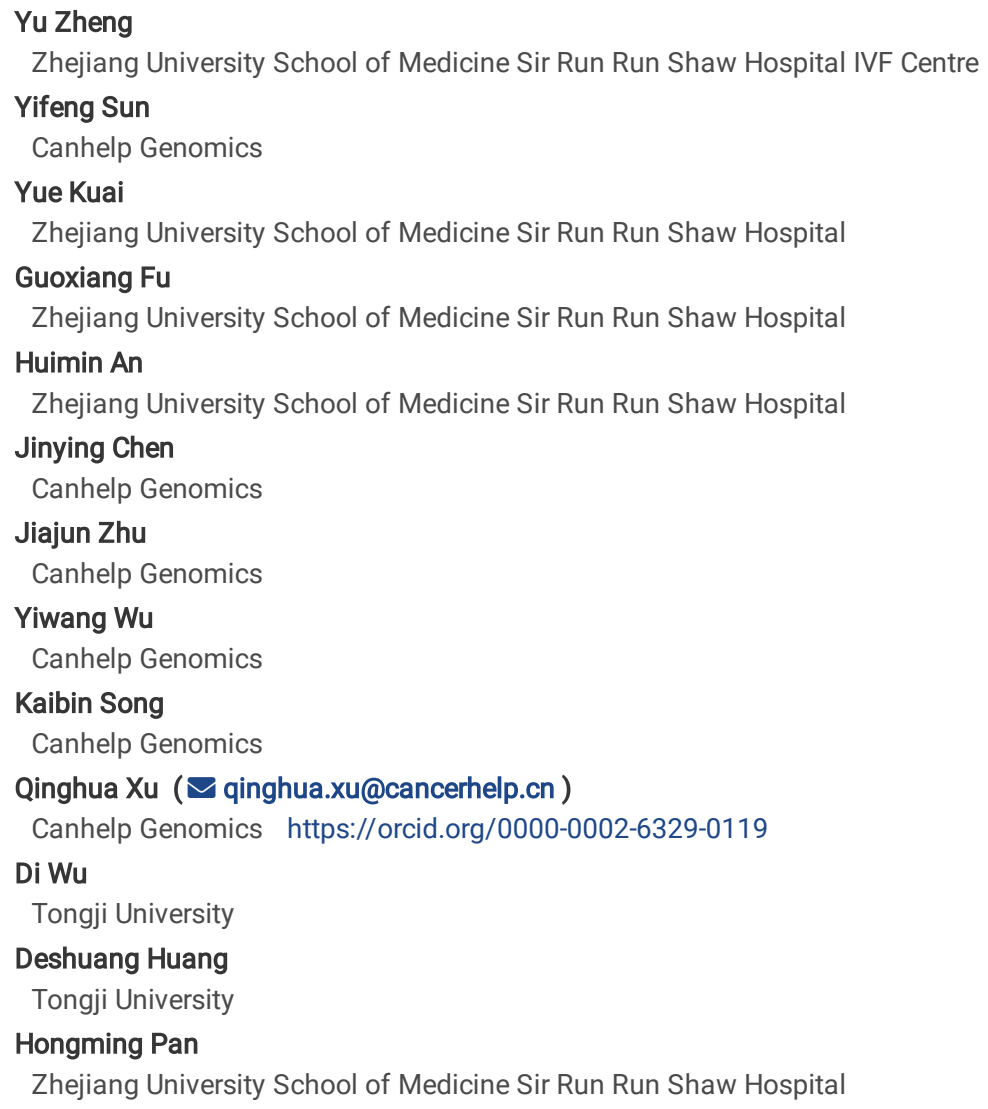

Version of Record: A version of this preprint was published at Cancer Cell International on January 12th, 2021. See the published version at https://doi.org/10.1186/s12935-021-01748-8. 


\section{Abstract}

Background: The incidence of multiple primary malignant tumors (MPMTs) is rising due to the development of screening technologies, significant treatment advances and the increased aging of the population. For patients with a prior cancer history, distinguishing tumor recurrence or metastasis from a second malignant tumor has important prognostic and therapeutic implications and still represents a difficult problem in clinical practice.

Methods: In this study, we evaluated the performance of a 90-gene expression assay and explored its potential diagnostic utility for MPMTs across a broad spectrum of tumor types. Twenty-four MPMT patients from Sir Run Run Shaw Hospital, college of medicine, Zhejiang University were enrolled in this study. A total of 51 MPMT specimens met all quality control criteria and were analyzed by the 90-gene expression assay.

Results: For each clinical specimen, the tumor type predicted by the 90-gene expression assay was compared with its reference diagnosis with an overall accuracy of $94.1 \%$ (48 of $51,95 \%$ confidence interval: $0.83-0.98$ ). Additionally, the hierarchical clustering of 90 -gene expression profiling in 51 specimens revealed MPMT samples were grouped together depending on tumor types or system types rather than individual MPMT patients.

Conclusions: Therefore, the 90-gene expression assay provides flexibility and accuracy in identifying the tissue origin of MPMTs, especially in squamous cell carcinoma. Future incorporation of the 90-gene expression assay in the pathological diagnosis will assist oncologists in applying precise treatments, leading to improved care and outcomes for MPMT patients.

\section{Introduction}

Multiple primary malignant tumors (MPMTs) are defined as two or more histologically distinct malignancies in one individual. With the development of screening technologies as well as significant treatment advances, early detection and precise treatment have led to a dramatic increase in the population of cancer survivors. In addition to this increase in the population of cancer survivors, the incidence of MPMTs is also rising due to the increased aging of the population [1]. A previous study revealed that the frequency of MPMTs varies between $2.4 \%$ and $8 \%$, and is up to $17 \%$ within 20 years of follow-up [2]. In China, two epidemiological studies reported that 0.99 to $1.09 \%$ of cancer patients could develop a second primary malignancy [3, 4]. The risk of developing MPMTs varies across tumor types; it is most common for bladder cancer as the first primary tumor, and lung cancer is the most commonly second primary tumor [5].

For patients with a prior cancer history, distinguishing tumor recurrence or metastasis from a second malignant tumor has important prognostic and therapeutic implications and still represents a difficult problem in clinical practice. In the clinic, histopathologic analysis could help characterize the tissue origin in most cases. However, tumor heterogeneity and interobserver variation between pathologists can cause confusion, especially when metastatic foci are poorly differentiated or undifferentiated [6].

In recent years, gene expression profiling has been widely studied and has become a powerful tool in distinguishing origin of tumors. Previous studies have suggested the clinical utility of gene expression profiling in distinguishing synchronous primary malignancies of the ovary and endometrium or metastatic spread from either the ovary or the endometrium, as well as in distinguishing between second primary lung cancer and lung metastasis from head and neck tumors $[7,8]$. However, few data support the broad application of gene expression profiling for MPMTs.

Previously, we developed a 90-gene expression assay for the classification of 21 common tumor types by using quantitative real-time polymerase chain reaction (qRT-PCR) methods with total RNA extracted from formalin-fixed, paraffin-embedded (FFPE) tissue [9]. In a validation study that included more than 600 clinical samples, the 90 -gene expression assay demonstrated an overall accuracy of $90.2 \%$ for primary tumors (292/323) and $87.3 \%$ for metastatic tumors (255/286). In addition, Wang et al. applied the 90-gene expression assay for the differential diagnosis of metastatic triple-negative breast cancer (TNBC) [10]. The results show that the molecular assay correctly classified $97.6 \%$ of TNBC lymph node metastases (41/42) and $96.8 \%$ of distant metastatic tumors (30/31). Zheng et al. investigated the 90-gene expression assay for diagnosing the tissue origin of brain tumors [11]. The molecular assay showed $100 \%$ accuracy for discriminating primary brain tumors from brain metastases and correctly predicted primary sites for $89 \%$ of brain metastases (39/44). Recently, Ning et al. also demonstrated the strengths of the 90-gene expression assay in distinguishing multiple primary squamous cell carcinomas in head and neck, esophagus, and lung cancers [12]. In this study, we evaluated the performance of the 90-gene expression assay and explored its potential diagnostic utility for MPMTs. Our results show that this PCR-based gene expression assay might serve as a useful tool for identifying the tissue origin of MPMTs.

\section{Methods And Materials}

\section{Sample selection}

This study was approved by the institutional review board of Sir Run Run Shaw Hospital, College of Medicine, Zhejiang University (Hangzhou, China). FFPE tissue samples from 27 patients (56 specimens) archived from July 2013 to December 2016 were used in this study. All samples were excisional biopsies and histopathologically confirmed as MPMTs according to the international diagnostic criteria of Warren and Gate [13]. The tumor that was first diagnosed and associated with the cause of the patient's initial visit was defined as the first primary cancer, the second diagnosed tumor was considered the second cancer and so forth. According to the Surveillance Epidemiology and End Results (SEER) definitions, all of the first tumors in MPMT patients diagnosed within six months are classified as synchronous MPMTs, and tumors diagnosed after more than six months are deemed metachronous MPMTs [2]. Hematoxylin and eosin (H\&E)-stained slides from tumor samples were reviewed by pathologists to evaluate the percentage of tumor cells and necrotic areas. If fewer than $60 \%$ of the tumor cells or greater than $40 \%$ of the necrotic area was present on inspection, regions of interest were circled on the H\&E-stained slides, and the corresponding areas from unstained FFPE tissue sections were then manually macrodissected for tumor enrichment.

\section{Sample preparation and RNA isolation}


The tumor tissue from five to fifteen 5 - $\mu$ m-thick paraffin sections was scraped and placed into a $1.5 \mathrm{~mL}$ microcentrifuge tube. Total RNA was isolated from FFPE samples using an FFPE Total RNA Isolation Kit (Canhelp Genomics, Hangzhou, China) as described previously [14]. Briefly, FFPE tissue was deparaffinized by sequential washing in xylene at $50^{\circ} \mathrm{C}$ for $3 \mathrm{~min}$ and twice in $100 \%$ ethanol. Proteins were digested with proteinase $\mathrm{K}$ solution at $56^{\circ} \mathrm{C}$ for 15 min and then for another $15 \mathrm{~min}$ at $80^{\circ} \mathrm{C}$, following treatment with DNase. Total RNA was eluted from the spin column with $40 \mu \mathrm{L}$ RNase-free water. The total RNA concentration was assessed by a NanoDrop 2000 Spectrophotometer (Thermo Fisher Scientific, Wilmington, DE, United States) at 260 nm, and the purity of extracted total RNA was determined by the ratio of absorbance at $260 \mathrm{~nm}$ to that at $280 \mathrm{~nm}$ (A260/A280). qRT-PCR analyses were only performed on RNA samples with $\mathrm{A} 260 / \mathrm{A} 280$ ratios between 1.7 and 2.1 .

\section{Expression profiling of 90 tumor-specific genes}

The qRT-PCR method was used to measure the gene expression levels of 90 tumor-specific genes corresponding to 21 major tumor types as previously described (Additional Table 1\&2) [10]. For each sample, reverse transcription was performed on isolated total RNA using a High-Capacity cDNA Reverse Transcription Kit with RNase Inhibitor (Applied Biosystems, Foster City, CA, United States). Subsequently, qRT-PCR was performed using the 7500 Real-Time PCR system (Applied Biosystems) to measure the 90 gene expression levels. The PCR cycling conditions were 10 min at $95^{\circ} \mathrm{C}$ and 40 cycles of 15 seconds at $95^{\circ} \mathrm{C}$ and $1 \mathrm{~min}$ at $60^{\circ} \mathrm{C}$.

\section{Data analysis}

The gene expression for each sample was analyzed by the 90-gene expression assay. Then, similarity scores for each of 21 tumor types were calculated, which showed similarities in the gene expression pattern between the sample and the indicated tumor type [15] The similarity score values ranged from 0 (very low similarity) to 100 (very high similarity), which summed up to 100 across all 21 tumor types. The tumor type with the highest similarity score was considered to indicate the tissue of origin. An example of the result from the 90-gene expression assay is shown in Additional Figure 1.

For each clinical specimen, the predicted tumor type was compared with its reference diagnosis. The clinical diagnostic accuracy was defined as the number of correctly predicted cases divided by the total number of enrolled cases. The hierarchical clustering of the data matrix was performed using R software with the pheatmap package (version 1.0.12).

\section{Results}

\section{Patients and samples}

Twenty-seven patients with a total of 56 specimens were enrolled from Sir Run Run Shaw Hospital, College of Medicine, Zhejiang University in this study. Two patients were excluded due to the high content of necrotic tissue in the samples, and one patient was excluded because of insufficient tumor content. Twentyfour MPMTs from 51 specimens met all quality control criteria and were analyzed by the 90-gene expression assay. Based on the invasion site of the tumor, 51 specimens were sorted into five groups: the digestive system (gastroesophagus, colorectum and liver), urinary system (kidney, urinary and prostate), breast, lung, and head and neck (tongue and thyroid). Table 1 presents the demographics of the 24 MPMT patients. Among these patients, 20 harbored synchronous MPMTs, and four harbored metachronous MPMTs. Seventeen patients were male and seven patients were female. The median age at diagnosis was 62.5 (range 45-77) for the first cancer, 63 (range 45-77) for the second cancer and 68 (range 53-70) for the third cancer. The most common invasion sites of the first, second and third tumors were all in the digestive system. Of the 51 specimens, tumors were most frequently located in the colorectum (29.4\%, 15 of 51$)$, gastroesophagus (17.6\%, 9 of 51), breast $(9.8 \%, 5$ of 51$)$ and lung $(11.8 \%, 6$ of 51$)$. The distribution of tumor locations is shown in Figure 1 . The most common stages of the first, second and third cancers were II, I/II and I/II, respectively. Twenty-three out of 24 patients (95.8\%) underwent surgery, and $45.8 \%$ $(11 / 24)$ underwent chemotherapy.

\section{Performance of the 90-gene expression assay in MPMTs}

The overall workflow for the 90-gene expression assay is shown in Figure 2. The concentrations of total RNA from 51 samples ranged from $7.3 \mathrm{ng} / \mu \mathrm{L}$ to 214.3 $\mathrm{ng} / \mu \mathrm{L}$, with a median of $66.6 \mathrm{ng} / \mu \mathrm{L}$. The median A260/A280 ratio (purity of RNA) was 1.98 (range 1.74-2.04).

With the 90-gene expression assay, 16 specimens were classified as colorectal tumors, 9 as gastroesophageal tumors, 6 as breast tumors, 5 as lung tumors, 4 as urinary tumors, 4 as kidney tumors, 2 as liver tumors, 2 as prostate tumors, 2 as thyroid tumors and 1 as head and neck tumors. For the 51 specimens, the 90-gene expression assay showed an overall agreement of $94.1 \%$ (48 of 51, 95\% confidence interval (Cl): $0.83-0.98)$. Table 2 shows the performance of the 90 gene expression assay in subgroups compared with the reference diagnosis. Twenty-seven digestive system tumors comprised colorectal ( $\mathrm{n}=15)$, gastroesophageal $(n=9)$ and liver $(n=3)$ tumors. The overall agreement for digestive system tumors was $92.6 \%(25$ of $27,95 \%$ Cl: $0.74-0.99)$, with subgroup accuracy ranging from $66.7 \%$ (liver) to $100 \%$ (colorectum). In an analysis of the urinary system tumors, the concordance rates were $100 \%$ for classifying tumors from the kidney $(n=4)$, urinary $(n=4)$ and prostate $(n=2)$. In addition, the 90 -gene expression assay correctly classified $100 \%$ of the breast cancer cases $(n=5), 100 \%$ of the head and neck cancer cases $(n=3)$ and $83.3 \%$ of the lung cancer cases $(n=6)$.

To investigate the similarities between clinical samples, hierarchical clustering of the 51 tumors by 90 -gene expression profiles was performed. As shown in Figure 3 , the hierarchical clustering of 90 -gene expression profiling in 51 specimens revealed distinct patterns between the five system types. Samples were grouped together depending on tumor or system types rather than individual MPMT patients.

Three specimens had discordant predictions compared with the reference diagnosis. Detailed clinical information is provided in Table 3. The histological types of the three misclassified samples were pulmonary mucoepidermoid carcinoma, poorly differentiated gastric antrum adenocarcinoma and poorly differentiated gallbladder adenocarcinoma. The 90-gene expression assay misclassified pulmonary mucoepidermoid carcinoma as breast cancer, gastric 
antrum adenocarcinoma as colorectal cancer, and gallbladder adenocarcinoma as gastroesophageal cancer. For 48 cases that were concordant with the reference diagnosis, the median similarity score was 88 (range 42.8-99.2), while the similarity scores of three misclassified samples were relatively low (38, 49.9 and 56.8). A distribution plot of the highest similarity scores for 51 specimens related to tumor types is displayed in Additional Figure 2.

\section{Specific case}

A 77-year-old man noticed chest tightness, shortness of breath, nausea/vomiting and fever. He underwent endoscopic biopsies (29-35 $\mathrm{cm}$ from the incisors) and was diagnosed with squamous cell carcinoma (SCC). In the meantime, a chest computed tomography (CT) scan found a lesion in the left upper lung, and the lung biopsy was diagnosed as SCC. Through comprehensive clinical and pathology examination, the clinician confirmed that the patient had multiple synchronous primary tumors according to the Warren and Gates criteria [13]. FFPE tumor tissues taken from the esophagus and lung were analyzed by the 90gene expression assay, and the predictions showed that the two specimens were gastroesophageal cancer (similarity score $=75.9)$ and lung cancer (similarity score $=91.7)($ Figure 4).

SCC comprises a wide range of tumors originating from diverse anatomical locations that share a common histomorphology and expression of squamous cell differentiation markers, making it difficult to distinguish whether the subsequent SCC is a primary tumor or metastatic lesion. This patient had two lesions on the esophagus and lung simultaneously. Histopathologically, esophageal SCC often metastasizes to the lung. Pathological diagnosis could only confirm the two lesions in the esophagus and lung as SCCs. It was difficult to determine whether the two lesions were synchronous SCCs or represented SCC metastasis based on immunohistochemistry (IHC) and morphology assessment. Clinical outcome of synchronous esophageal and lung SCCs is better than that of metastatic cancer, and the diagnosis of the tumor will directly affect the choice of treatment options. If the new lesion is a second primary tumor, surgical resection supplemented by chemotherapy or radiotherapy has been the preferred therapeutic regimen instead of palliative treatment. Thus, in patients highly suspected of having metastatic cancer, the use of a 90-gene expression assay may be able to identify the tissue of origin more quickly when imaging and IHC examinations are ineffective and could help guide the choice of the precise treatment regimen.

\section{Discussion}

Currently, with the significant development in tumor screening and diagnostic tools, the detection rate of MPMTs is higher than before. Additionally, the appearance of new treatment methods, including targeted therapy and immunotherapy, helps cancer patients achieve longer survival. Therefore, the likelihood of cancer survivors having a second malignancy is higher than before because of the longer follow-up times. Lindsay et al. found that the occurrence of cancer survivors developing second cancers rose dramatically from 9\% in 1975-1979 to 19\% in 2005-2009 [16]. The distinction between MPMTs and the recurrence or metastasis of primary cancer is crucial for selecting the treatment strategy. A second cancer could be cured by radical operation supplemented by chemotherapy and/or radiotherapy, which is similar to the treatment of single primary cancer. In contrast, recurrent or metastatic tumors indicate that the primary tumor had progressed to advanced stages. Palliative treatment is the first choice for recurrence or metastasis of the primary tumor. For the people who develop a second primary cancer, $13 \%$ die from their original cancer, and $55 \%$ died from their second primary cancer [5]. Thus, how to diagnose tumors as metastatic or a second primary cancer accurately and in a timely manner is becoming more important.

In clinical settings, histopathologic analysis could identify the possible tissue of origin to distinguish between MPMTs and the recurrence or metastasis of primary cancer. However, morphological and IHC analyses are not able to identify the tissue of origin of poorly differentiated or undifferentiated tumors. In addition, for patients with multiple SCC lesions, pathologists cannot give a definite diagnosis after microscopic assessment because of the similar histologic appearances among SCCs. Anderson et al. found that IHC panels provide an accuracy of $65.6 \%$ for identifying primary sites of metastatic tumor samples [17]

Previous studies have demonstrated that gene expression profiling between primary and metastatic tumors showed a high degree of similarity [6, 9]. Efforts have been made to use gene expression profiling to distinguish the second primary tumor from metastatic recurrence. Charles et al. found that gene expression profiling could accurately identify $89 \%$ of metastatic tumors, whereas $\mathrm{IHC}$ achieved $83 \%$ agreement. In poorly differentiated or undifferentiated subsets, gene expression profiling correctly distinguished $91 \%$ of cases compared to $71 \%$ agreement using the IHC method [18]. Anita et al. developed a gene expression profiling test for distinguishing between synchronous primary malignancies of the ovary and endometrium or metastatic spread from either the ovary or the endometrium and achieved good performance, with an accuracy of $94.7 \%(71 / 75)$ [7]. Another study also reported by Anital et al. determined if a new lung nodule was a second primary or a lung metastasis from a head and neck tumor with an accuracy of 82.9\% (63/76) [8]. However, few studies have validated the performance of gene expression profiling in MPMTs across a broad spectrum of tumor types.

In the present study, we described the investigation of an effective and efficient approach for the molecular classification of MPMTs. Similar to findings from previous studies $[10,11]$, the success rate of the 90-gene expression assay was excellent $(91 \%, 51 / 56)$, even for samples archived five years prior to analysis, indicating satisfactory performance for this assay with FFPE samples. This may be critical for widespread access and application in clinical practice. The 90 gene expression assay classified 51 MPMT samples into ten cancer types and reached an overall accuracy of 94.1\% (48/51) when compared with the reference diagnosis. To the best of our knowledge, this is the first report of a gene expression assay that can be used to classify MPMTs into a wide range of cancer types. These results implied that the 90-gene expression signature might serve as a useful tool for identifying the tissue origin of MPMTs.

Although the 90-gene expression assay showed accuracy and robustness in classifying MPMTs, three case diagnoses were discordant with the reference diagnosis. As shown in Table 3, one patient with a breast cancer history was diagnosed with left main bronchus mucoepidermoid carcinoma and duodenal adenocarcinoma seven years later. The biopsy specimen taken from the left main bronchus was misclassified as breast cancer. Another case was diagnosed as synchronous lung adenocarcinoma and gallbladder cancer. The 90-gene expression assay correctly classified the lung cancer specimens but misclassified the gallbladder cancer specimen as a gastroesophageal tumor. These errors are likely due to the underrepresentation bias of gallbladder cancer and bronchus mucoepidermoid carcinoma among the 90-gene specific pan-cancer transcriptome database [15], given that gallbladder cancer was not included in the database and mucoepidermoid carcinoma only accounts for $0.1 \%-0.2 \%$ of all pulmonary tumors [19]. The third case was diagnosed as synchronous triple

Page $4 / 12$ 
primary tumors in the rectum, gastric antrum and gastric cardia. The specimens taken from rectum and gastric cardia were correctly classified, but gastric adenocarcinoma in the gastric antrum was misclassified as colorectal cancer. Further histopathologic analysis confirmed that the gastric adenocarcinoma specimen was poorly differentiated and that large intestine metaplasia was found around the tumor area.

\section{Conclusion}

In conclusion, the results of this study demonstrate the promising performance of the 90-gene expression assay in identifying the tissue origin of MPMTs. In cases in which the morphological and IHC work-up cannot confirm the tissue of origin, the 90-gene expression assay may serve as a useful tool for discriminating second primary tumors and recurrence or metastasis of primary cancer, especially in SCC. Future incorporation of the 90 -gene expression assay in the pathological diagnosis will assist oncologists in applying precise treatments, leading to improved care and outcomes for MPMT patients

\section{List Of Abbreviations}

CT: Computed tomography

FFPE: Formalin-fixed, paraffin-embedded

H\&E: Hematoxylin and eosin

IHC: Immunohistochemistry

MPMTs: Multiple primary malignant tumors

qRT-PCR: Quantitative real-time polymerase chain reaction

SCC: Squamous cell carcinoma

SEER: Surveillance Epidemiology and End Results

TNBC: Triple-negative breast cancer

\section{Declarations}

\section{Ethics approval and consent to participate}

Ethics approval and consent to participate for the study were obtained from the Clinical Research Ethics Committee of Sir Run Run Shaw Hospital, College of Medicine, Zhejiang University, Ethical code: 20171109-3.

\section{Consent for publication}

Not applicable

\section{Availability of data and materials}

Not applicable

\section{Competing interests}

Author YF S, JY C, JJ Z, YW W, KB S and QH X were employed by the company Canhelp Genomics. The remaining authors declare that the research was conducted in the absence of any commercial or financial relationships that could be construed as a potential conflict of interest.

\section{Funding}

This work was partially supported by Zhejiang Provincial Natural Science Foundation of China (Grant No. LSY19H160006) and Canhelp Genomics Co., Ltd.

\section{Authors' contributions}

Y Z, YF S, QH X and HM P designed the study. Y K and JJ Z collected clinical samples and clinical information. YF S, JY C, GX F, HM A and YW W performed the experiments. Y Z, YF S, KB S, QH X and D W analyzed all data. Y Z and YF S wrote the initial manuscript draft. QH X, DS H and HM P critically revised the manuscript and gave valuable insight to the study concept. All authors revised the manuscript. All authors read and approved the final manuscript.

\section{Acknowledgements}

Not applicable

\section{References}


1. Morton LM, Onel K, Curtis RE, Hungate EA, Armstrong GT: The rising incidence of second cancers: patterns of occurrence and identification of risk factors for children and adults. Am Soc Clin Oncol Educ Book 2014:e57-67.

2. Vogt A, Schmid S, Heinimann K, Frick H, Herrmann C, Cerny T, Omlin A: Multiple primary tumours: challenges and approaches, a review. ESMO Open 2017, 2:e000172.

3. Liu Z, Liu C, Guo W, Li S, Bai O: Clinical Analysis of 152 Cases of Multiple Primary Malignant Tumors in 15,398 Patients with Malignant Tumors. PLOS ONE 2015, 10:e0125754.

4. Zhai C, Cai Y, Lou F, Liu Z, Xie J, Zhou X, Wang Z, Fang Y, Pan H, Han W: Multiple Primary Malignant Tumors - A Clinical Analysis of 15,321 Patients with Malignancies at a Single Center in China. Journal of Cancer 2018, 9:2795-2801.

5. Donin N, Filson C, Drakaki A, Tan HJ, Castillo A, Kwan L, Litwin M, Chamie K: Risk of second primary malignancies among cancer survivors in the United States, 1992 through 2008. Cancer 2016, 122:3075-3086.

6. Weiss LM, Chu P, Schroeder BE, Singh V, Zhang Y, Erlander MG, Schnabel CA: Blinded comparator study of immunohistochemical analysis versus a 92gene cancer classifier in the diagnosis of the primary site in metastatic tumors. J Mol Diagn 2013, 15:263-269.

7. Lal A, Panos R, Marjanovic M, Walker M, Fuentes E, Kapp DS, Henner WD, Buturovic LJ, Halks-Miller M: A Gene Expression Profile Test for the Differential Diagnosis of Ovarian Versus Endometrial Cancers. Oncotarget 2012, 3:212-223.

8. Lal A, Panos R, Marjanovic M, Walker M, Fuentes E, Kubicek GJ, Henner WD, Buturovic LJ, Halks-Miller M: A gene expression profile test to resolve head \& neck squamous versus lung squamous cancers. Diagn Pathol 2013, 8:1-11.

9. Ye Q, Wang Q, Qi P, Chen J, Sun Y, Jin S, Ren W, Chen C, Liu M, Xu M, Ji G. Development and Clinical Validation of a 90-Gene Expression Assay for Identifying Tumor Tissue Origin. The Journal of Molecular Diagnostics. 2020 Jun 28.

10. Wang Q, Xu M, Sun Y, Chen J, Chen C, Qian C, Chen Y, Cao L, Xu Q, Du X, Yang W: Gene Expression Profiling for Diagnosis of Triple-Negative Breast Cancer: A Multicenter, Retrospective Cohort Study. Front Oncol 2019, 9:115.

11. Zheng Y, Ding Y, Wang Q, Sun Y, Teng X, Gao Q, Zhong W, Lou X, Xiao C, Chen C, Xu Q, Xu N: 90-gene signature assay for tissue origin diagnosis of brain metastases. J Transl Med 2019, 17:1-9.

12. Qu N, Huang D, Xu Q, Wang J, et CCAB, 2020: Gene expression profiling of cells of origin of squamous cell carcinomas in head-and-neck, esophagus, and lung. academicoupcom.

13. WARREN S: Multiple primary malignant tumors. A survey of the literature and a statistical study. Am J Cancer 1932, 16:1358-1414.

14. Wang Q, Gan H, Chen C, Sun Y, Chen J, Xu M, Weng W, Cao L, Xu Q, Wang J: Identification and validation of a 44-gene expression signature for the classification of renal cell carcinomas. J Exp Clin Cancer Res 2017, 36:176.

15. Xu Q, Chen J, Ni S, Tan C, Xu M, Dong L, Yuan L, Wang Q, Du X: Pan-cancer transcriptome analysis reveals a gene expression signature for the identification of tumor tissue origin. Mod Pathol 2016, 29:546-556.

16. Morton LM, Onel K, Curtis RE, Hungate EA, Armstrong GT: The rising incidence of second cancers: patterns of occurrence and identification of risk factors for children and adults. Am Soc Clin Oncol Educ Book 2014:e57-67.

17. Anderson GG, Weiss LM: Determining tissue of origin for metastatic cancers: meta-analysis and literature review of immunohistochemistry performance. Appl Immunohistochem Mol Morphol 2010, 18:3-8.

18. Handorf CR, Kulkarni A, Grenert JP, Weiss LM, Rogers WM, Kim OS, Monzon FA, Halks-Miller M, Anderson GG, Walker MG, Pillai R, Henner WD: A multicenter study directly comparing the diagnostic accuracy of gene expression profiling and immunohistochemistry for primary site identification in metastatic tumors. Am J Surg Pathol 2013, 37:1067-1075.

19. Li X, Guo Z, Liu J, Wei Sen, Ren D, Chen G, Xu S, Chen J: Clinicopathological characteristics and molecular analysis of primary pulmonary mucoepidermoid carcinoma: Case report and literature review. Thoracic Cancer 2018, 9:316-323.

\section{Tables}


Table 1

Patients and tumors characteristics included in this study

\begin{tabular}{|c|c|c|c|}
\hline & First Cancer* & Second Cancer & Third Cancer \\
\hline \multicolumn{4}{|l|}{ Gender, \% } \\
\hline Male & $17(71)$ & & \\
\hline Female & $7(29)$ & & \\
\hline \multicolumn{4}{|l|}{ Age at diagnosis } \\
\hline Mean & 62.5 & 63 & 68 \\
\hline Range & $45-77$ & $45-77$ & $53-70$ \\
\hline \multicolumn{4}{|l|}{ Type, \% } \\
\hline Synchronous & $20(83)$ & & \\
\hline Metachronous & $4(17)$ & & \\
\hline \multicolumn{4}{|l|}{ Stage, $\%$} \\
\hline I & $6(25)$ & $10(42)$ & $2(50)$ \\
\hline$\|$ & $10(42)$ & $10(42)$ & $2(50)$ \\
\hline III & $7(29)$ & $4(16)$ & $0(0)$ \\
\hline IV & $1(4)$ & $0(0)$ & $0(0)$ \\
\hline \multicolumn{4}{|l|}{ Invasion site, \% } \\
\hline Digestive system & $14(58)$ & $11(46)$ & $3(75)$ \\
\hline Urinary system & $4(17)$ & $5(21)$ & $1(25)$ \\
\hline Breast & $2(8)$ & $3(12)$ & $0(0)$ \\
\hline Lung & $2(8)$ & $4(17)$ & $0(0)$ \\
\hline Head \& Neck & $2(8)$ & $1(4)$ & $0(0)$ \\
\hline \multicolumn{4}{|l|}{ Treatment } \\
\hline Surgery & 23 & & \\
\hline Chemotherapy & 11 & & \\
\hline \multicolumn{4}{|l|}{ Histology, \% } \\
\hline Well-differentiated & & $33(65)$ & \\
\hline Poorly differentiated & & $13(25)$ & \\
\hline Squamous cell carcinoma & & $5(10)$ & \\
\hline
\end{tabular}


Table 2

Performance of 90-gene expression assay in MPMTs

\begin{tabular}{|llll|}
\hline Tumor Type & Number & Agreement & Agreement \\
\hline Digestive system & 27 & 25 & $92.6 \%$ \\
\hline Colorectum & 15 & 15 & $100.0 \%$ \\
\hline Gastroesophagus & 9 & 8 & $88.9 \%$ \\
\hline Liver & 3 & 2 & $66.7 \%$ \\
\hline Urinary system & 10 & 10 & $100.0 \%$ \\
\hline Kidney & 4 & 4 & $100.0 \%$ \\
\hline Urinary & 4 & 4 & $100.0 \%$ \\
\hline Prostate & 2 & 2 & $100.0 \%$ \\
\hline Head \& Neck & 3 & 3 & $100.0 \%$ \\
\hline Thyroid & 2 & 2 & $100.0 \%$ \\
\hline Tongue & 1 & 1 & $100.0 \%$ \\
\hline Breast & 5 & 5 & $100.0 \%$ \\
\hline Lung & 6 & 5 & $83.3 \%$ \\
\hline Total Accuracy & & & $94.1 \%$ \\
\hline
\end{tabular}

Table 3

Investigation of cases with discordant 90-gene expression assay results

\begin{tabular}{|c|c|c|c|c|c|c|c|c|c|c|}
\hline ID & Gender & Type & $\begin{array}{l}\text { First } \\
\text { /Second/Third }\end{array}$ & Age & $\begin{array}{l}\text { Reference } \\
\text { diagnosis }\end{array}$ & Grade & $\begin{array}{l}90 \text {-gene } \\
\text { expression assay } \\
\text { results }\end{array}$ & $\begin{array}{l}\text { Highest } \\
\text { Similarity } \\
\text { Score }\end{array}$ & $\begin{array}{l}\text { cTMN } \\
\text { stage }\end{array}$ & $\begin{array}{l}\text { pTMN } \\
\text { stage }\end{array}$ \\
\hline 1 & Female & Metachronous & $\begin{array}{l}\text { Second } \\
\text { Cancer }\end{array}$ & 67 & $\begin{array}{l}\text { Left main } \\
\text { bronchus } \\
\text { mucoepidermoid } \\
\text { carcinoma }\end{array}$ & l & Breast & 38 & $\begin{array}{l}\text { T1N0M0, } \\
\text { I }\end{array}$ & $\begin{array}{l}\text { T1N0M0, } \\
\text { I }\end{array}$ \\
\hline 2 & Male & Synchronous & Third Cancer & 68 & $\begin{array}{l}\text { Gastric antrum } \\
\text { adenocarcinoma }\end{array}$ & $\begin{array}{l}\text { Moderately } \\
\text { and poorly } \\
\text { differentiated }\end{array}$ & Colorectum & 56.8 & $\begin{array}{l}\text { T1N0M0, } \\
\text { IA }\end{array}$ & $\begin{array}{l}\text { T1NOM0, } \\
\text { IA }\end{array}$ \\
\hline 3 & Female & Synchronous & $\begin{array}{l}\text { Primary } \\
\text { Cancer }\end{array}$ & 50 & $\begin{array}{l}\text { Gallbladder } \\
\text { adenocarcinoma }\end{array}$ & $\begin{array}{l}\text { Moderately } \\
\text { and poorly } \\
\text { differentiated }\end{array}$ & Gastroesophagus & 49.9 & TxNOMO & $\begin{array}{l}\text { T3NOMO, } \\
\text { IIA }\end{array}$ \\
\hline
\end{tabular}

\section{Figures}




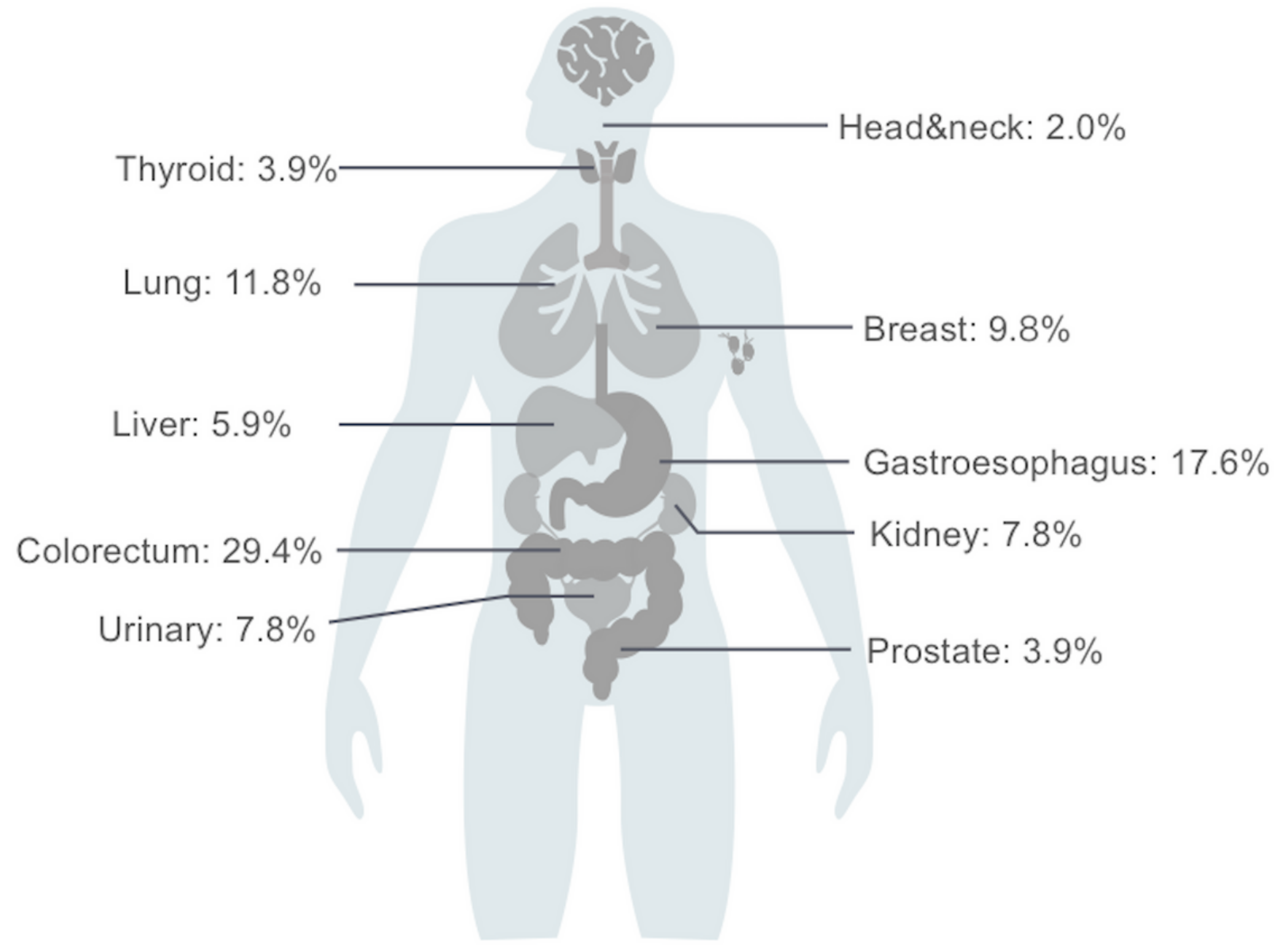

Figure 1

The distribution of tumor types for MPMT patients. 

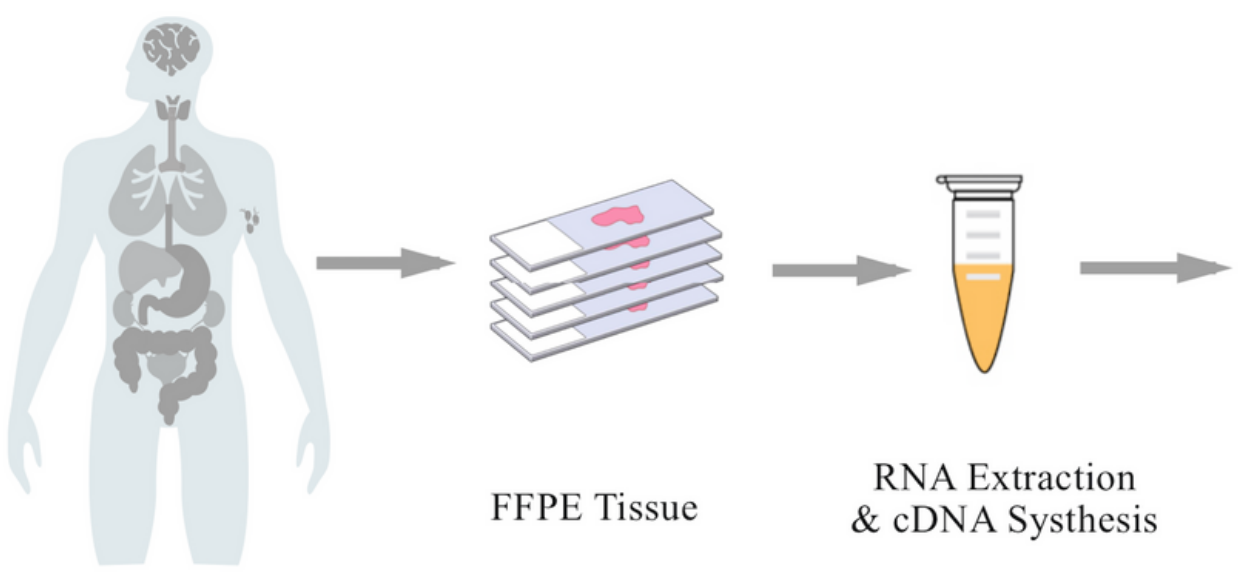

$\begin{array}{llllllllllll}1 & 2 & 3 & 4 & 5 & 6 & 7 & 8 & 9 & 10 & 11 & 12\end{array}$ A (19) (1) 2 3) (4) 58 (7) (10) B (11) (12) (13) (14) (15) (16) (17) (18) (1) 21 (21) (22) C 23 (24) 25 (26) 27 (28) 29 (31) (31) 32 (33) 34

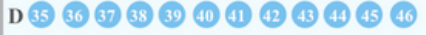
E (47) (48) (49) (51) (52) 33 (4) 57575

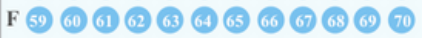

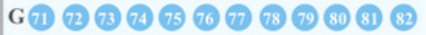

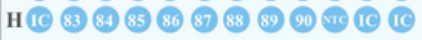

RNA Extraction \& cDNA Systhesis
FFPE Tissue

\section{0-gene expression assay}
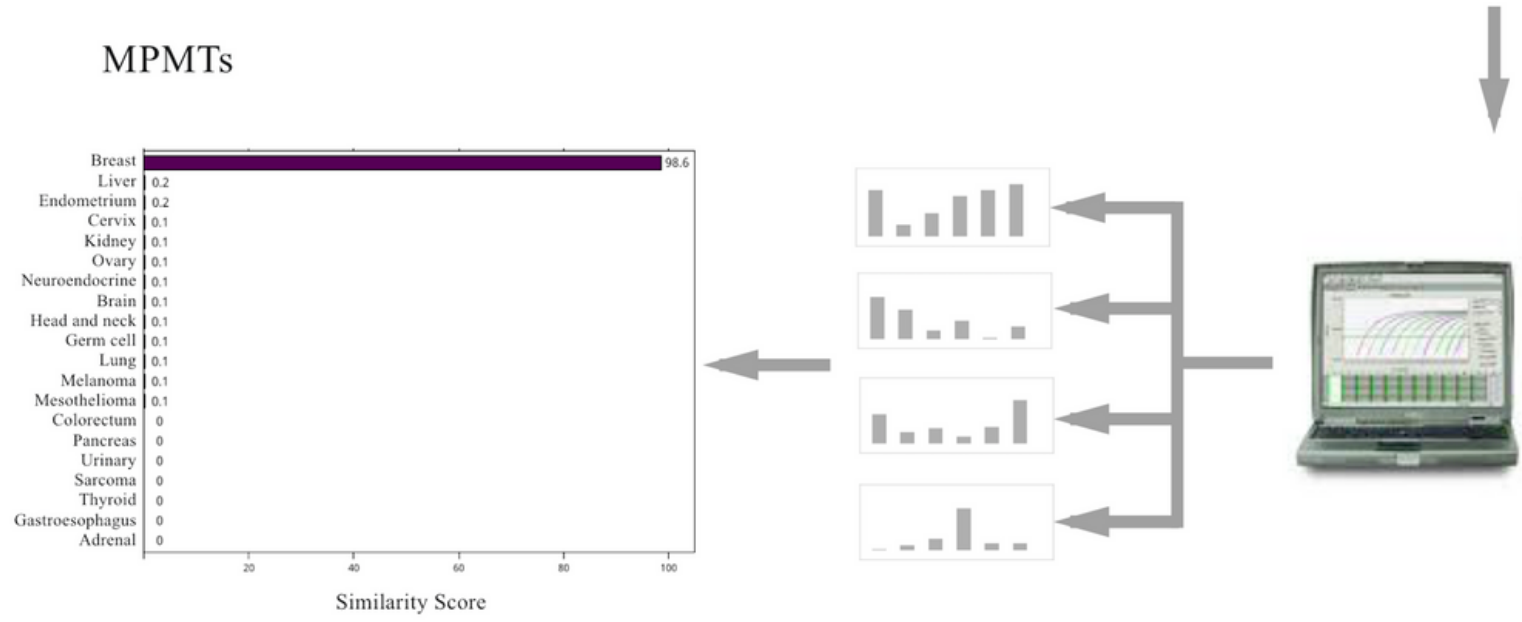

90-gene expression assay result

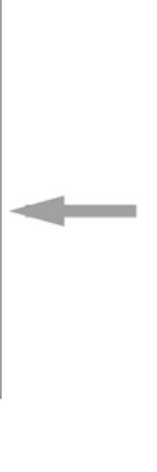

Data analysis system
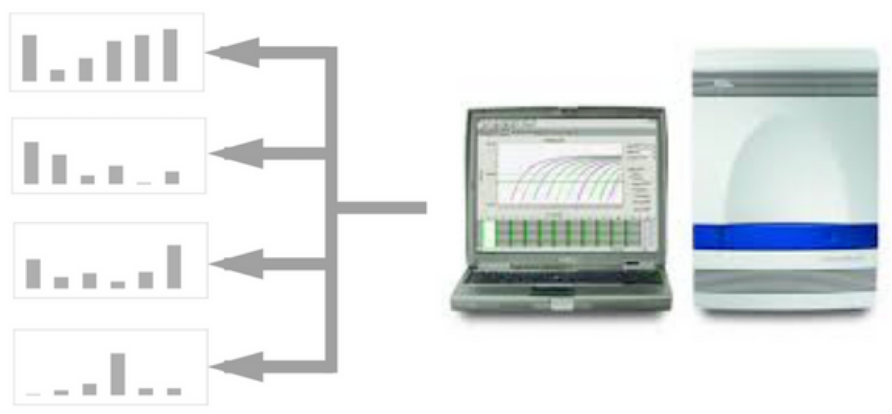

qRT-PCR

\section{Figure 2}

The workflow of the study. FFPE tissues collected from MPMT patients were used for RNA extraction and qRT-PCR analysis. The gene expression profiling was analyzed by 90 -gene signature with one similarity score for each of the 21 tumor types. The top three predictions were breast (98.6), liver (0.2) and endometrium (0.2), thereby the most likely site is breast (98.6). 


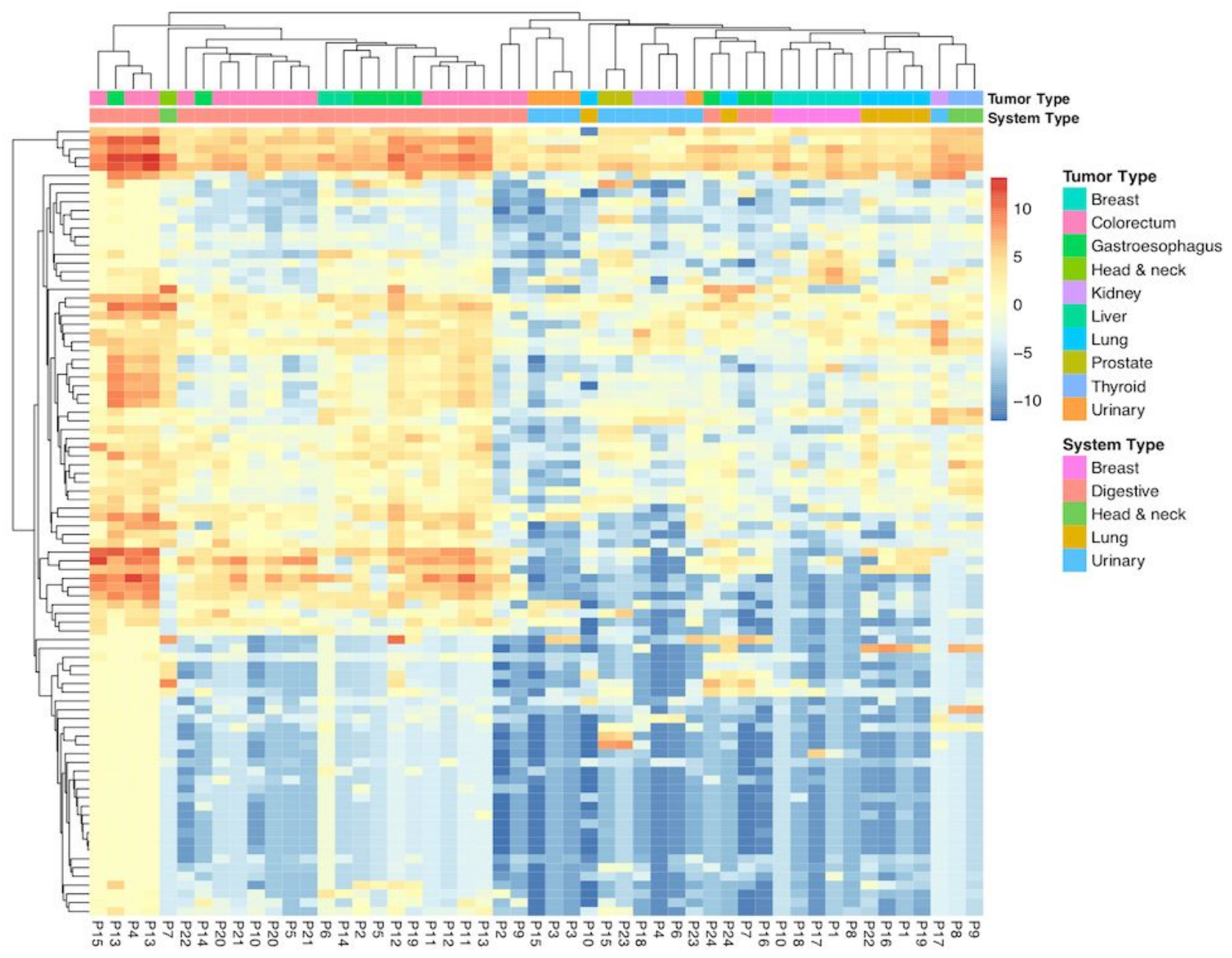

\section{Figure 3}

Hierarchical clustering analysis of 90 genes in 51 specimens. The left panel shows a dendrogram of hierarchical clustering of 90 genes. Coloured pixels capture the magnitude of the expression for any gene, where shades of red and blue represent over-expression and under-expression, respectively, relative to the mean for each gene. The upper panel shows a dendrogram of hierarchical clustering of samples. Tumor type and system type of each sample are indicated in the upper panel. The bottom panel indicates the patient number.

A

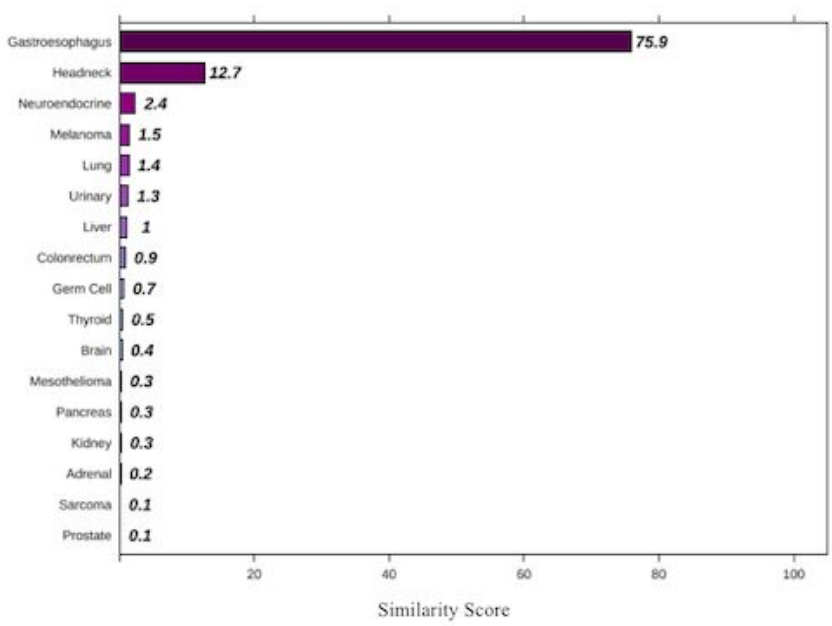

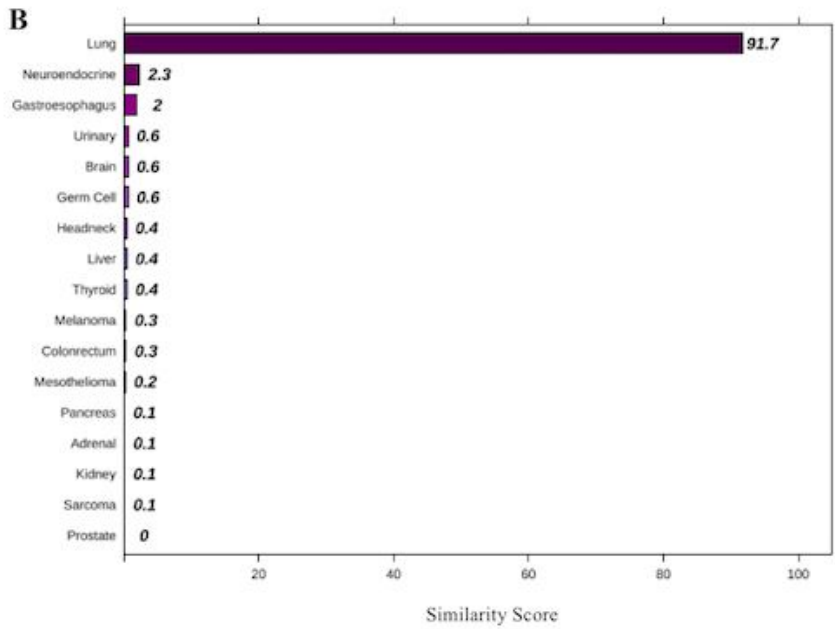

\section{Figure 4}

The 90-gene expression assay results of specific case. (A) esophagus lesion (B) lung lesion. 


\section{Supplementary Files}

This is a list of supplementary files associated with this preprint. Click to download.

- AdditionalFiles.docx

- AdditionalTable2.xls

- AdditionalTable1.xls

- AdditionalFigure2.tiff

- AdditionalFigure1.tiff 